\title{
Optimizing smoothed sea surface temperature for improving archival tag geolocation
}

\author{
Benjamin Galuardi ${ }^{1, *}$, Anders Nielsen ${ }^{2}$, Molly Lutcavage ${ }^{1}$ \\ ${ }^{1}$ Large Pelagics Research Lab, 177 Spaulding Hall, University of New Hampshire, Durham, New Hampshire 03824, USA \\ ${ }^{2}$ Pelagic Fisheries Research Program, Joint Institute for Marine and Atmospheric Research, University of Hawai'i at Manoa, \\ 1000 Pope Road, MSB 312, Honolulu, Hawaii 96822, USA
}

\begin{abstract}
Pop-up satellite archival tags (PSATs) and data loggers (archival tags) have become key tools for tracking movements of marine animals, but uncertainties in location estimates can range from tens to hundreds of kilometers. Sea surface temperature (SST) may be used in models to improve light-based geolocation by comparing SSTs measured in tags to those measured by satellites (e.g. with a Kalman filter). Daily SST measurements are retrieved from the data recorded in the tag by averaging the near surface temperatures. Raw satellite SST data are represented as points in a grid, but measurement noise and areas missing due to cloud cover can produce an uneven SST field that may not correspond well with the local average of SST measured by the tags. A smoothed satellite SST field is used to compensate for these problems. We used 2 crossvalidation schemes to analyze what degree of smoothing produces the optimal match with the SST from the tag. Simulations based on data returned by PSATs deployed on Atlantic bluefin tuna Thunnus thynnus are used as a test case. We demonstrate that the optimal scale of smoothing, which affects overall variance in any type of geolocation estimation, is influenced by the scale of diffusive animal movement and that treatment of satellite SST in a geolocation framework should be carefully considered. The developed crossvalidation scheme provides an objective method for choosing the optimal smoothing scale and allows for better control of the overall geolocation process.
\end{abstract}

KEY WORDS: Satellite SST · Kalman filter · Local polynomial regression · Animal movement · Bluefin tuna $\cdot$ Thunnus thynnus

- Resale or republication not permitted without written consent of the publisher

\section{INTRODUCTION}

Despite the great interest, economic value, and conservation concerns for highly migratory fishes such as tunas, sharks, and billfish, gaps remain in our understanding of their movements and behavior. The U.S. Atlantic bluefin tuna Thunnus thynnus fishery has experienced a sharp drop in catch in recent years (NMFS Fisheries Statistics Division pers. comm.), and in the Mediterranean Sea, both quotas and reported catches are exceeding scientific recommendations by 2- to 3-fold (ICCAT 2007). Obtaining the most accurate biological information possible is essential for management of this important resource (Fromentin \& Powers 2005). Pop-up satellite archival tags (PSATs) have become an essential tool for monitoring migration and delivering critical habitat information for highly migratory species (e.g. Lutcavage et al. 1999, Arnold \& Dewar 2001, Block et al. 2001, Gunn \& Block 2001). Although PSATs are reliable for identification of largescale movements and deliver depth and temperature information at high resolution, the light-based position information returned from these tags may be unrealistic, often containing errors of hundreds of kilometers (Sibert et al. 2003, Teo et al. 2004, Wilson et al. 2005, Nielsen et al. 2006).

Various forms of state space models estimated via Kalman filters (Kalman 1960) have become popular choices for obtaining positions from tunas and other animals tagged with light-based archival and PSATs (Musyl et al. 2001, Sibert \& Fournier 2001, Royer et al. 2005, Nielsen et al. 2006). Remotely sensed sea surface 
temperature (SST) can be incorporated into these models to improve geolocation accuracy of archival and pop-up satellite tags (Nielsen et al. 2006). These methods incorporate tag-measured sea surface temperatures in the measurement equations, and require independent spatial and temporal representation of surface temperature to aid position estimation (see Nielsen et al. 2006, equations 1 to 3). The Kalman filter sea surface temperature (KFSST) package (Nielsen \& Sibert 2005) is a library for the R statistical language (Ihaka \& Gentleman 1996) that can accommodate temperature information through an extended Kalman filter (EKF) framework. Its predecessor, KFtrack, has been used to estimate locations of bluefin tuna tagged with PSATs in the northwest Atlantic Ocean (Wilson et al. 2005, Sibert et al. 2006) and bigeye tuna Thunnus obesus positions from archival tags in the Pacific Ocean (Sibert et al. 2003). The use of SST to aid geolocation was first suggested by Smith \& Goodman (1986), and has since been used in various longitude-SST matching schemes (e.g. Teo et al. 2004, Domeier et al. 2005).

SST imagery often has gaps due to cloud coverage and the swath of the satellite sensor's coverage. To have representation at all possible locations, SST imagery gaps must be corrected or estimated. Most archival tags today are capable of measuring temperature and depth, and deliver either time series or binned data. With KFSST, tag measurements of SST are added to the observation equations of the EKF as a single daily measurement. Additionally, the local derivatives of the satellite SST field are required to estimate the local linear approximation of SST used in the EKF equations (Nielsen et al. 2006). A challenge arising from the use of this new approach is that fish are mobile and SST is heterogeneous. The KFSST model uses a daily tag-based SST measurement corresponding to the light-based geolocation for the day. One way to obtain the daily tag SST measurement is to average all of the depth-applicable measurements from that day. This average, therefore, is an average of SST from the area covered by the fish, and corresponds to a smoothed SST field. The optimal scale at which to smooth satellite SST is, therefore, related to the scope of an animal's movement, and it becomes necessary to use smoothed SST in the EKF framework (Nielsen et al. 2006).

Nielsen et al. (2006) used local polynomial fitting (Loader 1999) to smooth satellite SST data, used with drifting GPS buoys with thermistors and attached PSATs, in a double tagging study in the subtropical waters surrounding the Hawaiian Islands. The initial sensitivity analysis in that study yielded little difference between nearest neighbor bandwidths of 2.5, 5 and $10 \%$ using $1^{\circ}$ Reynolds (Reynolds \& Smith 1994) and Advanced
Very High Resolution Radiometer (AVHRR) 9 km resolution SST data. Results from this study indicated that variance of the final estimates could be reduced using these products in the Kalman filter framework, but did not explore optimal smoothing.

Geolocation correction may further benefit from retention of strong or highly variable temperature structure such as frontal boundaries and eddies. Western boundary current areas such as the Gulf Stream in the Atlantic Ocean and the Kuroshio Current in the Pacific Ocean have strong latitudinal and longitudinal thermal gradients, and can be highly variable on small spatial scales. Since gaps in the data must be filled in, the question arises as to how much smoothing will fill in the gaps while retaining enough structure to be useful. Too much smoothing can remove too much temperature structure, while insufficient smoothing can produce noisy imagery, which would hinder the likelihood-based minimization routines in the EKF. In the present case, pop-up archival tags may remain attached on bluefin tuna up to a year and record surface temperatures from a vast area (e.g. Wilson et al. 2005). In addition, implanted archival tags (that must be recovered from the fish) have data logging capacities of several years (e.g. Gunn et al. 1994, Block et al. 1998, Inagake et al. 2001, Musyl et al. 2001). We attempt to derive an optimal bandwidth across a broad geographic and temporal range of dynamic temperate ocean, the northwest Atlantic, on a scale used by bluefin tuna, sea turtles, whales and other large marine animals. To determine optimal-smoothing bandwidths best suited for this region, 2 analyses are presented using crossvalidation schemes on both broad and local scales.

\section{MATERIALS AND METHODS}

The study area was the northwest Atlantic Ocean from 16.5 to $53.5^{\circ} \mathrm{N}$ and 87.5 to $47.5^{\circ} \mathrm{W}$, covering more than 18 million $\mathrm{km}^{2}$. This area was chosen to include both temperate and subtropical water and represents the area that tagged Atlantic bluefin tuna inhabited in previous studies (Lutcavage \& Newlands 1999, Block et al. 2005, Wilson et al. 2005, Sibert et al. 2006). To reduce loss of temperature structure, smaller smoothing bandwidths were used than in Nielsen et al. (2006). Here, smoothing bandwidths are defined as a percentage of nearest neighbors used in smoothing. Local temperature structure becomes more important when animal movement is localized, and less so when a large area is covered each day. In these cases, the temperature structure at a larger scale is more indicative of daily conditions encountered. If directed movement occurs along a frontal boundary, local temperature structure will remain important for the duration of the track (Lutcavage et al. 2000, Marcinek et al. 2001). 
Data. In 2002 and 2003, 128 Atlantic bluefin tuna were tagged and released with PSATs in the Gulf of Maine $(2002, \mathrm{~N}=66 ; 2003, \mathrm{~N}=61)$ and North Carolina (January 2003, $\mathrm{N}=1$ ), returning a series of geolocations along with depth and temperature records (Wilson et al. 2005).

We acquired Moderate Resolution Imaging Spectrometer (MODIS, v. 4.10.11, level 3 mapped), Terra and AVHRR (v. 5) data and associated quality flags from NASA's Goddard Space Flight Center, (Greenbelt, Maryland) and Jet Propulsion Lab (Pasadena, California), respectively. The data were $4 \mathrm{~km}, 8 \mathrm{~d}$ mean composite products and were delivered in hierarchical data format (HDF). Remotely sensed SST is produced by the satellite instrument sensing the emissive heat radiated from the top few millimeters of the oceans surface. This 'skin' temperature (SSST) can be affected by insolation during daylight hours and can, therefore, be less indicative of the subsurface conditions (Brown \& Minnett 1999); so to minimize these effects we used nighttime imagery for both products. The global temperature accuracy of AVHRR imagery is 0.3 to $0.5^{\circ} \mathrm{C}$ while MODIS is $0.3^{\circ} \mathrm{C}$. Quality flags indicate which pixels are most likely to contain errors and range from 0 to 3 (best to worst) for MODIS, and from 1 to 7 (worst to best) for AVHRR composites. Poor quality pixels were removed (quality level $>0$ for MODIS and $<5$ for AVHRR), scaled to degrees Celsius and converted to ASCII XYZ files (e.g. longitude, latitude, SST). All composites were processed using Matlab v. 7 (Mathworks). We used products from June 2002 to June 2004.

K-fold crossvalidation of temperature fields. The first step to assess optimal bandwidth is to determine whether an optimal smoothing scale exists in the data through crossvalidation techniques. Six local polynomial regression bandwidths were applied to the 27 MODIS composites (July 2002 to February 2003) using the locfit (v.1.5-2) library for R. Four AVHRR composites, representing different seasons (July 4 to 11 and November 9 to 16, 2002, and February 10 to 17 and April 15 to 22, 2003), were assessed using 8 smoothing bandwidths (Table 1 ). The range of nearest neighbor smoothing was shifted slightly for the AVHRR composites and included a $10 \%$ nearest neighbor bandwidth.

We used K-fold crossvalidation (Efron \& Tibshirani 1993) to compare smoothed images with the original composites. The MODIS and AVHRR composites each had $10 \%$ of the data randomly removed as a test set, and a 2nd order local polynomial (locfit) with a unique bandwidth was fit to the remaining $90 \%$. This was repeated 9 times for a total of $\mathrm{K}=10$ iterations. The test statistic was the sum of the squared residuals between the model output and the test set divided by the num- ber of SST pixels in the original composite. Residuals were only calculated where SST data were present in the original image. This was repeated for each bandwidth and for all composites for a total of 60 and 80 fits per composite for MODIS and AVHRR, respectively. The test statistics were then plotted against bandwidths, and the bandwidth showing the lowest error was considered to be the best fit. K-fold crossvalidation was chosen because of a lower computational cost and because it is more appropriate for large datasets than other methods, such as 'leave one out' crossvalidation (e.g. Stone 1974).

Locfit smoothes data by generating representative weighted polynomial equations, usually quadratic or cubic, at evaluation points based on a percentage of nearest neighbors. This percentage is synonymous with bandwidth in our study and can also be represented as an area (Table 1). Weights are chosen automatically according to a tri-cubic kernel. Clouds can expand the nearest neighbor area because the nearest SST pixels may be farther away. Smoothed SST images are obtained through interpolation based on the coefficients from the generated polynomials. Interpolation may be made on a grid or to specific points within the original boundaries. Further local polynomial regression details are described in Loader (1999).

FishCV. The previous crossvalidation scheme corresponds to the hypothetical situation where the bluefin tuna stays at the same location within each $24 \mathrm{~h}$ period. Since they do not, the SSTs that the fish encountered daily will vary. The daily SST measurement from the tag, which is an average of the near surface (i.e. 0 to $8 \mathrm{~m}$ ) temperatures encountered in a $24 \mathrm{~h}$ period, should be expected to match a locally averaged (i.e. smoothed) SST field. Therefore, the smoothing

Table 1. Local polynomial regression bandwidths used in K-fold crossvalidation ( $\mathrm{a}=$ MODIS, $\mathrm{b}=\mathrm{AVHRR}$ ), FishCV (c) and visual (d) analyses and their corresponding nearest neighbor areas in the absence of clouds

\begin{tabular}{|lccc|}
\hline Bandwidth (\%) & $\mathrm{km}^{2}$ & $\mathrm{~km} /$ side & Analysis \\
\hline 10.00 & 1823508 & $1350 \times 1350$ & $\mathrm{~b}, \mathrm{c}$ \\
5.00 & 911754 & $955 \times 955$ & $\mathrm{a}, \mathrm{b}, \mathrm{c}$ \\
4.00 & 729404 & $854 \times 854$ & $\mathrm{C}$ \\
3.00 & 547053 & $740 \times 740$ & $\mathrm{C}$ \\
2.50 & 455877 & $675 \times 675$ & $\mathrm{a}, \mathrm{b}, \mathrm{c}$ \\
2.00 & 364702 & $604 \times 604$ & $\mathrm{~b}, \mathrm{c}, \mathrm{d}$ \\
1.00 & 182351 & $427 \times 427$ & $\mathrm{a}, \mathrm{c}, \mathrm{d}$ \\
0.75 & 136763 & $370 \times 370$ & $\mathrm{~d}$ \\
0.50 & 91175 & $302 \times 302$ & $\mathrm{a}, \mathrm{b}, \mathrm{c}, \mathrm{d}$ \\
0.30 & 54705 & $234 \times 234$ & $\mathrm{~d}$ \\
0.25 & 45588 & $214 \times 214$ & $\mathrm{a}, \mathrm{b}$ \\
0.20 & 36470 & $191 \times 191$ & $\mathrm{~b}, \mathrm{c}, \mathrm{d}$ \\
0.15 & 32041 & $179 \times 179$ & $\mathrm{C}, \mathrm{d}$ \\
0.10 & 18235 & $135 \times 135$ & $\mathrm{a}, \mathrm{b}, \mathrm{c}, \mathrm{d}$ \\
\hline
\end{tabular}


bandwidth that optimizes this match would be the most appropriate for estimating position. To match the data collection procedure more closely, we use the following crossvalidation, which we refer to as FishCV.

(1) Geolocations, $g$ = (longitude, latitude), are generated randomly without replacement within a study area.

(2) Daily tag-based surface temperatures are selected around these geolocations from an original SST composite, where SST is present, according to a bivariate Gaussian distribution, $\sim N(g, \operatorname{diag}[2 D])$ (Fig. 1), where $D$ is daily diffusivity.

(3) Temperature values are averaged for each geolocation.

(4) Residuals, or mean squared error (MSE) is calculated from averaged observations and the smoothed SST (2nd order polynomials using locfit) predicted at the simulated geolocations.

(5) Repeat Steps 1 to 4 for a range of composites and average MSE over time.

a
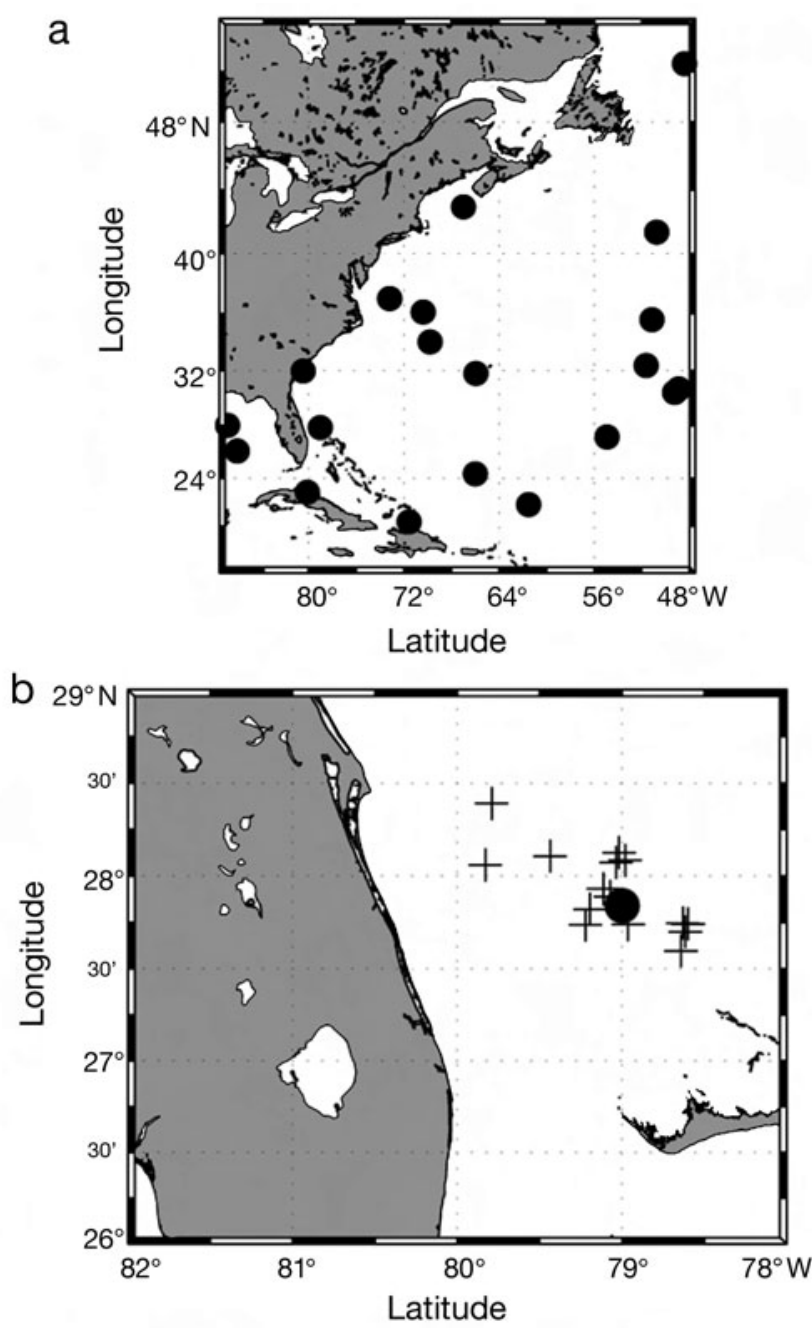

Fig. 1. Example of (a) 20 geolocation simulations (0) in the study area and (b) daily tag measured surface temperature observations $(+)$ around a simulated geolocation
(6) Plot MSE against smoothing bandwidth for each $D$, and the bandwidth that minimizes residual error is the most appropriate for a particular value of $D$.

In FishCV, $D$ is measured in nautical miles ${ }^{2} \mathrm{~d}^{-1}$ $(1 \mathrm{n}$ mile $=1.852 \mathrm{~km})$. KFSST assumes that the true location of the tracked individual can be approximated with a biased random walk on a plane, where $D$ is the diffusive part of the movement model representing the variance of the unknown true location (Nielsen \& Sibert 2005). The $D$ value can be considered as a scaling factor of the biased random walk (Okubo 1980, Sibert \& Fournier 2001), and makes it an appropriate parameter for determining an optimal SST smoothing scale based on daily movement.

We applied FishCV to 94 AVHRR composites from June 2002 to June 2004, spanning the duration of the 2002-2003 tagging efforts, using 11 local polynomial smoothing bandwidths (Table 1) and 20 geolocations per composite. We used 15 tag-based SSTs for each $g$, based on the number of hourly depth records between 0 and $8 \mathrm{~m}$ from several PSAT tagged bluefin tuna. Because optimal smoothing may be different when movements are restricted to small spatial scales, we tested daily observations, generated based on values of $D$ ranging from 0 to $1000 \mathrm{n}$ miles $^{2} \mathrm{~d}^{-1}$ (in $100 \mathrm{n}$ miles $^{2}$ $\mathrm{d}^{-1}$ increments, 10 total). To reduce the random variation, we ran the entire FishCV simulation twice. This resulted in MSE values, averaged through time, produced from a total of 4400 samples for each $D$ and bandwidth combination.

We also performed a visual assessment of the spatial structure of residual error from local polynomial SST smoothing by generating maps of time-averaged residual errors for 8 smoothing bandwidths (0.1 to $2.0 \%$ ) applied to 47 AVHRR composites from June 2002 to June 2003.

\section{RESULTS}

K-fold $(\mathrm{K}=10)$ crossvalidation results for both MODIS and AVHRR showed that composites fitted with smaller bandwidths had less error than those with larger bandwidths. Although local polynomial regression is less computationally intense than other methods, it was not possible to use bandwidths smaller than $0.1 \%$ due to the size of the study area and available computer time. Twenty-one of the 27 MODIS composites showed the smallest bandwidth, $0.1 \%(135 \times$ $135 \mathrm{~km})$, to be the best fit, and in the remaining six $0.25 \%(214 \times 214 \mathrm{~km})$ had the best fit. The AVHRR composites had a similar pattern of lowest error associated with smallest bandwidth (Fig. 2). No seasonal patterns were detected between July 2002 and February 2003. Of the 6 smoothing bandwidths applied to a MODIS image from July 2002, 2 illustrate where a 


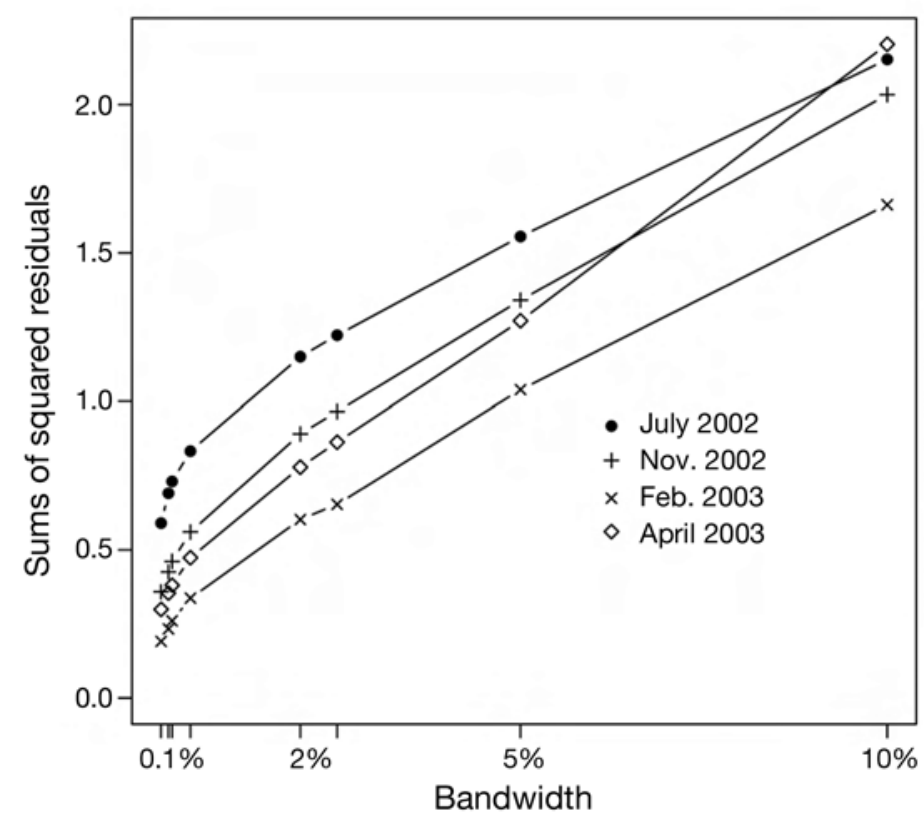

Fig. 2. AVHRR K-fold crossvalidation results show a trend of reduced residual error with decreasing bandwidth (smoothing percentage). All seasons examined showed a similar pattern

wider bandwidth produced a very smooth result, while a small bandwidth retained temperature structure (Fig. 3). The spatial structure of temporally averaged residuals showed that the north and south walls of the Gulf Stream had consistently higher residual error for all bandwidths, but most pronounced at larger bandwidths (Fig. 4). This was not surprising since the Gulf Stream edges are characterized by meanders and strong frontal regions, lending to weak spatial correlation of temperature. This was a qualitative indication of the spatial structure of locfit residuals.

The mean squared residuals (MSE), averaged through time, from our FishCV analysis were plotted against bandwidth to find where MSE was smallest, and, therefore, considered optimal, for each value of $D$ (Fig. 5). By plotting the optimal bandwidths against our $D$ values, a pattern emerged showing an increase of optimal bandwidth with an increase of $D$ (Fig. 6). This is an important finding as it shows that optimal smoothing bandwidth is dependent on animal movement over a wide range of ocean and time periods.

\section{DISCUSSION}

In our analysis of PSAT geolocations, K-fold crossvalidation was implemented to establish a lower bound for the smoothing parameter. While it is not surprising that results showed that the lowest values were most

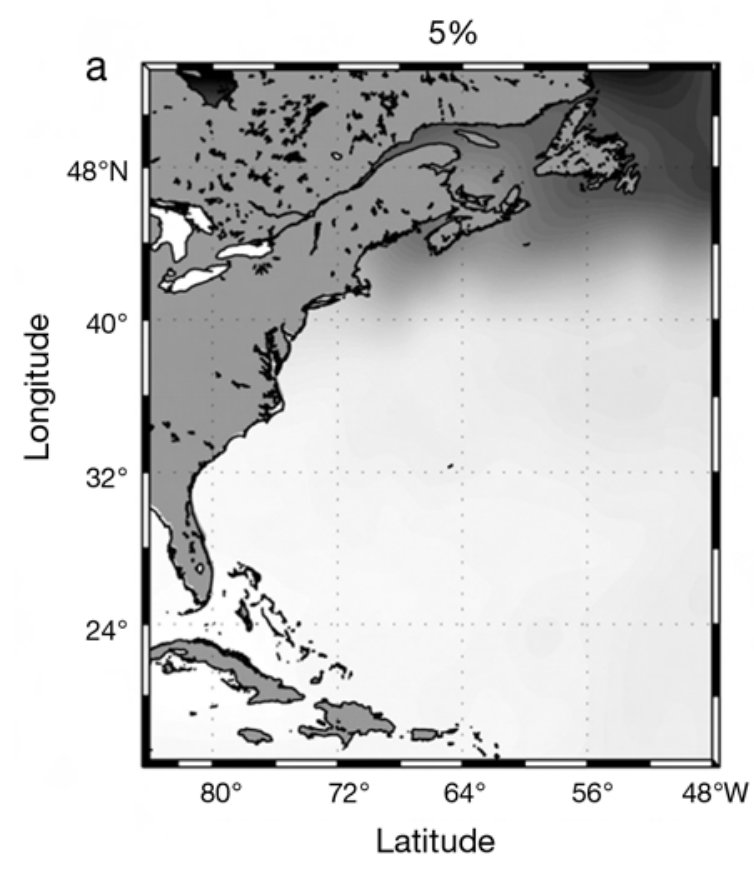

25

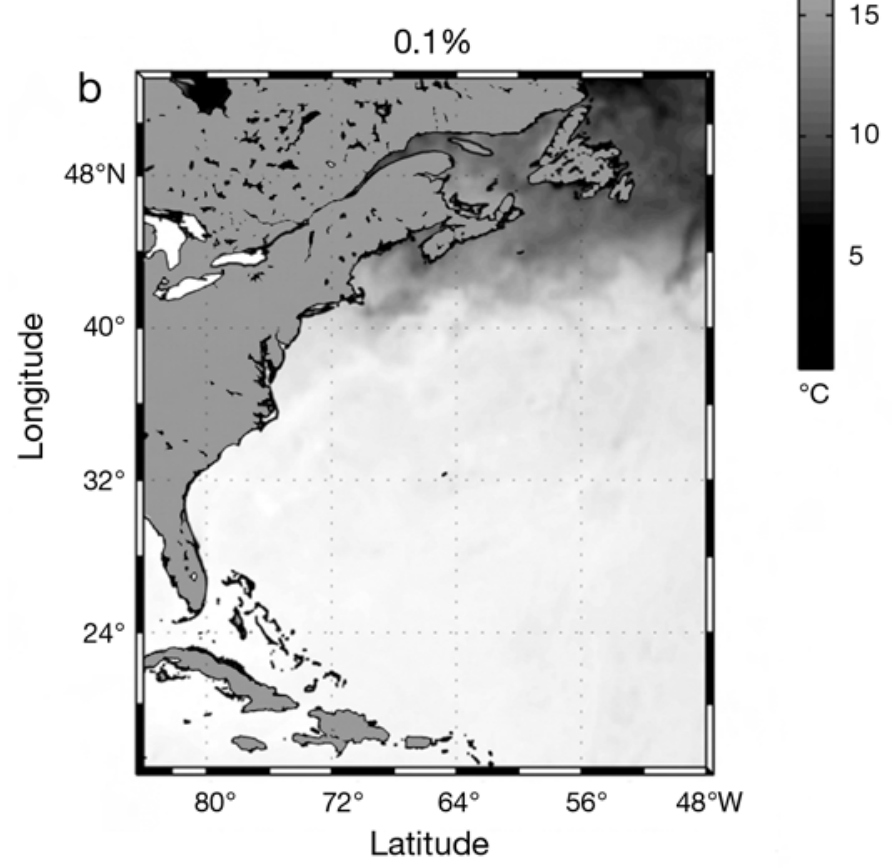

15

10

Fig. 3. An example of 2 smoothing bandwidths (5 and $0.1 \%$ ) applied to July 11-20, 2002 MODIS SST 8 d composite. The (a) larger $(5 \%)$ bandwidth smoothes out much of the temperature structure retained with (b) smaller $(0.1 \%)$ bandwidth

optimal, this technique is especially useful for new SST sources where measurement error is expected to remain in the data. It is possible that the limitations in minimum size of bandwidths selected and corresponding consideration areas did not allow for bandwidths small enough to identify an asymptotic pattern. We chose not to test FishCV using simulated animal tracks 


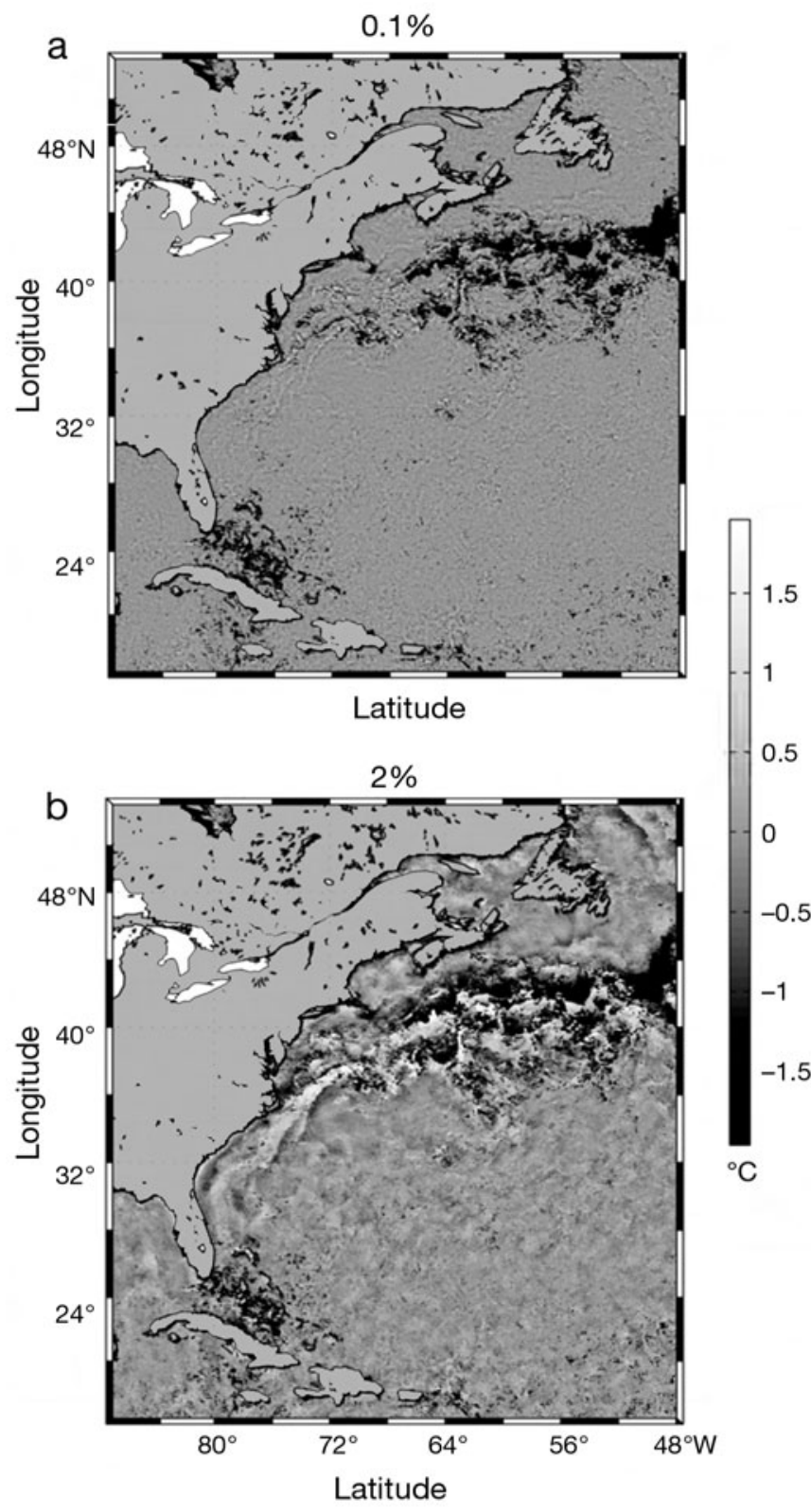

Fig. 4. Plot of time averaged mean residual values $\left({ }^{\circ} \mathrm{C}\right)$ for 2 bandwidths ( 2 and $0.1 \%$ ) of locally fitted AVHRR SST, June 2002 to June 2003, using quality flags $\geq 5$ only. Black areas indicate where data were unavailable at the selected quality level. Generally, the polynomial fits were quite accurate, especially at (a) small ( $0.1 \%)$ bandwidths, and became less accurate at (b) higher $(2 \%)$ bandwidths, particularly near the Gulf Stream

as this would result in sampling points close together rather than randomly apart. This provided the ability to test the relationship between $D$ and smoothing bandwidth in a greater area with fewer points than would be possible with alternative approaches.

Retention of temperature structure is potentially beneficial to the geolocation process, but there is always a tradeoff between resolution and benefits of smoothing applications (Worton 1987, Fan \& Gijbels 1995). This is apparent in an AVHRR image from March 2003, smoothed with the expected optimal $0.1 \%$ bandwidth (Fig. 7). Extensive cloudy areas combined with an evaluation using a small number of nearest neighbors can cause local anomalies in the interpolation phase. A wider bandwidth, which draws the polynomial representation from a larger area, will alleviate this problem. In these cases it would be better to either use SST smoothed with a larger bandwidth, or not use the composite at all. Removing it will leave gaps in the time series of smoothed composites, but should be less deleterious in KFSST estimation than using unrealistically smoothed images.

The spatial pattern of residual error fits with the Kfold results showing smallest error at smallest bandwidth. This result also agrees with SST models such as Mercator (CLS, Toulouse, France) which is least reliable near the Gulf Stream (Royer 2005). Gulf Stream edges are characterized by strong thermal fronts that shift seasonally, while rings and eddies often break off from the stream axis, affecting broad areas of ocean (e.g. The Ring Group 1981, Olson 2001). The combined effects characterize the dynamic nature of the northwest Atlantic Ocean and its boundary currents, and are examples of structure that may be lost when smoothing with large bandwidths.

Our FishCV analysis showed that the optimal bandwidth choice varies depending on diffusivity (the variability of the true movement). We showed that optimal bandwidth increases as $D$ increases. This fits theoretically as the larger an area that the daily surface temperature observations are drawn from, the less likely it is that the mean of those observations will match an actual value at their geographic mean. This would be most apparent in areas with strong thermal gradients, where daily observations may be sampled from either side of a thermal front, or where geolocation simulations occur in cloudy areas. FishCV can be used to identify bandwidths that should be acceptable or avoided, based on the tagged animal's diffusivity. Fig. 6 serves as a basic guide for smoothing SST prior to KFSST estimation using $4 \mathrm{~km}, 8 \mathrm{~d}$, AVHRR composites, but may be less valid for other SST sources.

In practice, $D$ is not known, but can be estimated using Kalman filters (Sibert \& Fournier 2001, Sibert et al. 2003, 2006) from mark-recapture information (Bertignac et al. 1998, Maury \& Gascuel 1999, Sibert et al. 1999), or may be obtained through Markov Chain Monte Carlo (MCMC) methods (Sibert et al. 2006). The MCMC approach would be useful if diffusivity was expected to change seasonally or during occupancy in particular areas. This scenario, combined with the prevalence of cloudy pixels in winter months in the northwest Atlantic Ocean, indicates that different bandwidths may be 


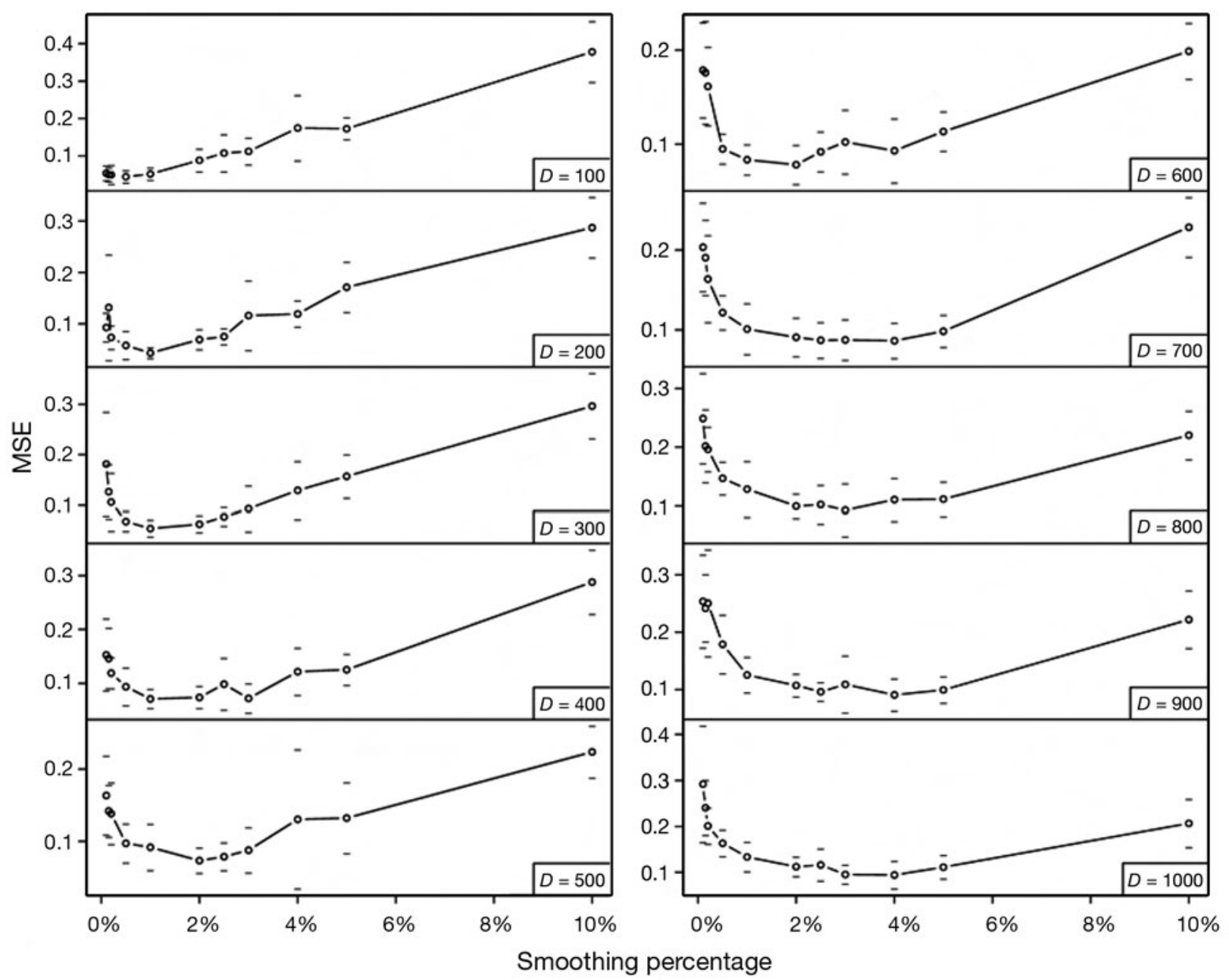

Fig. 5. Mean squared error (MSE) for 11 bandwidths (smoothing percentage) and $D$ between 100 and $1000 \mathrm{n} \mathrm{miles}^{2} \mathrm{~d}^{-1}$. The bandwidth where MSE is lowest is considered the optimal smoothing bandwidth for that value of $D$. Asymptotic patterns show that optimal smoothing exists towards the middle of the bandwidth choices considered, except in the case of $D=100$

optimal for SST smoothing during different periods of tag attachment, or when fish are in different geographic areas. A disadvantage of crossvalidation is that it is not able to compare interpolated data with observed data if there are no observations. The analyses in our study could only produce MSE if data were present in the original image. Visual inspection of the smoothed results remains an important step in choosing an appropriate local polynomial smoothing bandwidth. Comparisons with in situ data, SST models (such as Mercator products) or optimally interpolated products, such as Multi-Channel Sea Surface Temperature (MCSST), may also aid assessment of locally fitted SST.

Optimal smoothing of SST, therefore, has species and equipment specific components worth consideration. We chose values of $D$ that may be realistic for some species and not for others. Sibert et al. (2006), for example, reported a median estimate for $D$ of $317 \mathrm{n}$ miles for bluefin tuna tagged in 2002 in the Gulf

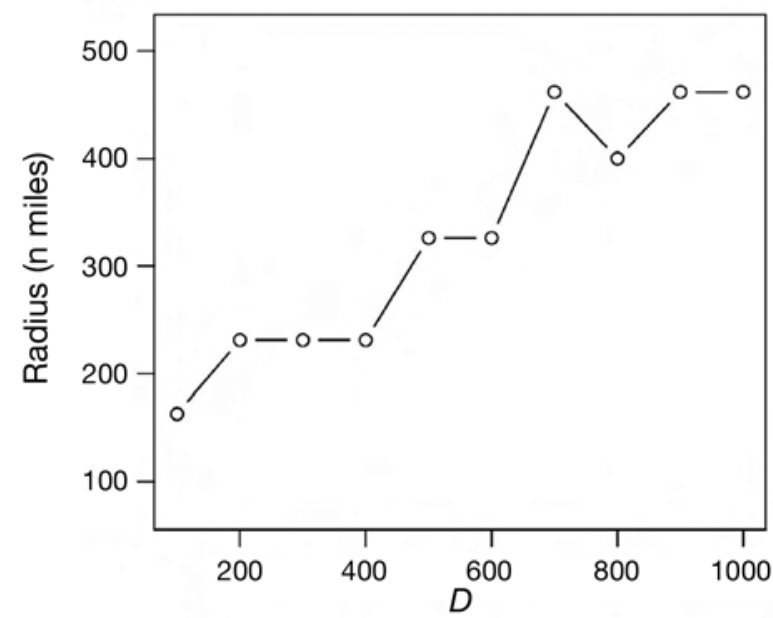

Fig. 6. Summary of optimal bandwidths (0) for values of daily diffusivity, $D$, between 100 and $1000 \mathrm{n}$ miles showing the general relationship between $D$ and optimal smoothing. As $D$ increases, optimal smoothing bandwidth (radius) increases 

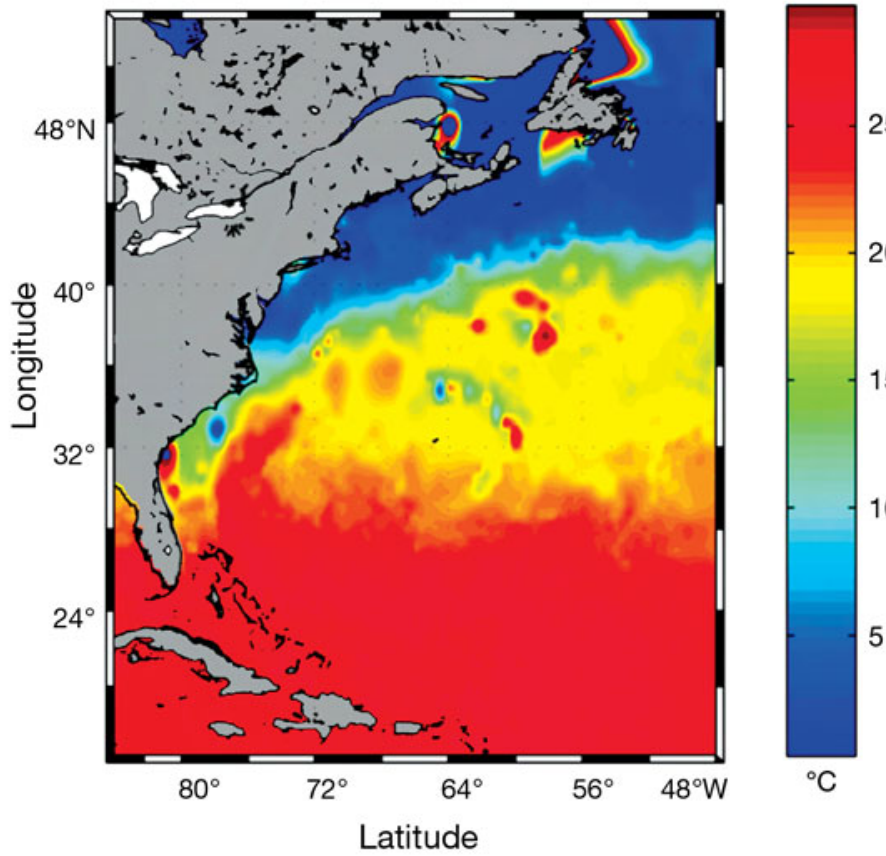

Fig. 7. March 14-21, 2003 AVHRR SST fitted with $0.1 \%$ local polynomial bandwidth; an example of a poor fit due to excessive cloudy areas

of Maine. For this dataset, a smoothing bandwidth of $230 \mathrm{n}$ miles (1\%) would be considered optimal based on Fig. 6. Alternatively, estimates of skipjack tuna Katsowonus pelamis diffusion parameters in the central and western Pacific Ocean can be much higher than values tested here (Sibert et al. 1996, 1999). Our definition of tag-measured SST was, likewise, a subjective decision for modeling purposes. Had we defined these differently, or examined tag data from other manufacturers, different assumptions about daily surface observations may have resulted. While FishCV is useful for finding an optimal smoothing bandwidth, it is only necessary to carry out a simulation using an approximate value of $D$ for the tracks being considered and satellite SST for the time period of interest.

\section{CONCLUSIONS}

Models for geolocation correction are constantly evolving and, as with any statistical technique, it is desirable to control as much variability as possible. Our work helps provide this for geolocation methods involving SST. The optimal amount of smoothing necessary for geolocation correction will be dependent on the scale of movement of the tagged animal. The crossvalidation scheme presented here provides an objective method for smoothing satellite SST by accounting for animal movement.
We used local polynomial regression, but other statistical methods such as Kriging (Cressie 1993) or Empirical Orthogonal Functions (EOF) may also work 25 well. Empirical Orthogonal Functions have been used for SST reconstruction in the Adriatic Sea (AlveraAzcarate et al. 2005) while Kriging has been used for 20 spatial interpolation in geologic and hydrologic applications in 2 and 3 dimensions (Cressie 1993). Kalman filter methods themselves could be used to recon15 struct cloudy pixels. Ensemble Kalman filters (EnsKF) (Evensen 1994), for example, have been used as a tool for optimal interpolation for temporally correlated data 10 such as temperature and salinity (Evensen 2003).

Satellite SST imagery is useful as a geolocation tool and can help reduce error in position estimation (Teo et al. 2004, Shaffer et al. 2005, Royer et al. 2005, 2006, Nielsen et al. 2006), but relatively little attention has been devoted to the choice of SST product or its implementation. Current schemes incorporate either a hierarchical framework, where fine resolution AVHRR or MODIS data are used when available and lower resolution products such MCSST are used in cloudy areas (Teo et al. 2004, Domeier et al. 2005), or a single product, smoothed to fill in missing data. Future work should take animal movement assumptions into account prior to the use of an SST product for geolocation correction. Optimal SST smoothness is related to animal movement, and determining this for individual species or tracks will be useful regardless of the geolocation correction method.

Acknowledgements. We thank J. R. Morrison, E. Linder, F. Royer and T. J. Miller for their helpful comments and advice, as well as A. B. Cooper and J. Sibert for explaining the intricacies of state space models. B. Galuardi was supported by a Marine Program graduate fellowship through the University of New Hampshire's Center for Excellence in Coastal Ocean and Analysis, and by NOAA grant NA04NMF4550391 to M.L. The work was partly sponsored by the University of Hawaii Pelagic Fisheries Research Program under cooperative agreement no. NA17RJ1230 from NOAA and a grant from the National Marine Fisheries Service (grant no. NA15FM2840).

\section{LITERATURE CITED}

Alvera-Azcarate A, Barth A, Rixen M, Beckers JM (2005) Reconstruction of incomplete oceanographic data sets using empirical orthogonal functions: application to the Adriatic Sea surface temperature. Ocean Model 9: 325-346

Arnold GP, Dewar H (2001) Electronic tags in marine fisheries research: a 30-year perspective. In: Sibert JR, Nielsen JL (eds) Electronic tagging and tracking in marine fisheries. Kluwer Academic Publishers, Dordrecht, p 7-64

Bertignac M, Lehodey P, Hampton J (1998) A spatial population dynamics simulation model of tropical tunas using a habitat index based on environmental parameters. Fish Oceanogr 7:326-334 
Block BA, Dewar H, Williams T (1998) Archival tagging of Atlantic bluefin tuna (Thunnus thynnus thynnus). Mar Technol Soc J 32:37-46

Block BA, Dewar H, Blackwell SB, Williams TD and others (2001) Migratory movements, depth preferences, and thermal biology of Atlantic bluefin tuna. Science 293: 1310-1314

Block BA, Teo SLH, Walli A, Boustany A and others (2005) Electronic tagging and population structure of Atlantic bluefin tuna. Nature 434:1121-1127

Brown OB, Minnett PJ (1999) MODIS infrared sea surface temperature algorithm. University of Miami, FL

Cressie NAC (1993) Statistics for spatial data. Wiley-Interscience, New York

Domeier ML, Kiefer D, Nasby-Lucas N, Wagschal A, O'Brien F (2005) Tracking Pacific bluefin tuna (Thunnus thynnus orientalis) in the northeastern Pacific with an automated algorithm that estimates latitude by matching sea-surfacetemperature data from satellites with temperature data from tags on fish. Fish Bull 103:292-306

Efron B, Tibshirani RJ (1993) An introduction to the bootstrap. Chapman \& Hall, London

Evensen G (1994) Sequential data assimilation with a nonlinear quasi-geostrophic model using Monte Carlo methods for forecast error statistics. J Geophys Res 99:10143-10162

Evensen G (2003) The Ensemble Kalman Filter: theoretical formulation and practical implementation. Ocean Dyn 53: 343-367

Fan J, Gijbels I (1995) Data-driven bandwidth selection in local polynomial fitting - variable bandwidth and spatial adaptation. J R Stat Soc B 57:371-394

Fromentin JM, Powers JE (2005) Atlantic bluefin tuna: population dynamics, ecology, fisheries and management. Fish Fish 6:281-306

Gunn J, Block BA (2001) Advances in acoustic, archival, and satellite tagging of tunas. In: Block BA, Stevens ED (eds) Tuna physiology, ecology, and evolution. Academic Press, San Diego, CA, p 167-224

Gunn JS, Polacheck T, Davis TL, Sherlock M, Betlehem A (1994) The application of archival tags to study the movement, behaviour and physiology of southern bluefin tuna, with comments on the transfer of the technology to groundfish research. In: Proceedings of ICES Mini-Symposium on Fish Migration. ICES, Copenhagen, p 23

ICCAT (2007) Report for biennial period, 2006-07 Part 1 (2006). International Commission for the Conservation of Atlantic Tuna, Madrid

Ihaka R, Gentleman R (1996) R: a language for data analysis and graphics. J Comput Graph Stat 5:299-314

Inagake D, Yamada H, Segawa K, Okazaki M, Nitta A, Itoh T (2001) Migration of young bluefin tuna, Thunnus orientalis, through archival tagging experiments and its relation with oceanographic conditions in the western North Pacific. Bull Natl Res Inst Far Seas Fish 38:53-81

Kalman R (1960) A new approach to linear filtering and prediction problems. Trans Am Soc Mech Eng (ASME) J Basic Eng 82(Ser D):35-45

Loader C (1999) Local regression and likelihood. SpringerVerlag, New York

Lutcavage M, Newlands N (1999) A strategic framework for fishery-independent aerial assessment of bluefin tuna. Col Vol Sci Pap ICCAT 49:400-402

Lutcavage ME, Brill RW, Skomal GB, Chase BC, Howey PW (1999) Results of pop-up satellite tagging of spawning size class fish in the Gulf of Maine: Do North Atlantic bluefin tuna spawn in the mid-Atlantic? Can J Fish Aquat Sci $56: 173-177$
Lutcavage M, Brill R, Skomal GB, Chase BC, Goldstein J, Tutein J (2000) Tracking adult North Atlantic bluefin tuna (Thunnus thynnus) in the northwestern Atlantic using ultrasonic telemetry. Mar Biol 137:347-358

Marcinek DJ, Blackwell SB, Dewar H, Freund EV and others (2001) Depth and muscle temperature of Pacific bluefin tuna examined with acoustic and pop-up satellite archival tags. Mar Biol 138:869-885

Maury O, Gascuel D (1999) SHADYS ('simulateur halieutique de dynamiques spatiales'), a GIS based numerical model of fisheries. Aquat Living Resour 12:77-88

Musyl MK, Brill R, Curran DS, Gunn JS and others (2001) Ability of archival tags to provide estimates of geographical position based on light intensity. In: Sibert JR, Nielsen JL (eds) Electronic tagging and tracking in marine fisheries. Kluwer Academic Publishers, Dordrecht, p 343-368

Nielsen A, Sibert JR (2005) The KFSST package available at https://www.soest.hawaii.edu/tag-data/tracking/kfsst/

Nielsen A, Bigelow K, Musyl MK, Sibert JR (2006) Improving light-based geolocation by incorporating sea surface temperature. Fish Oceanogr 15:314-325

Okubo A (1980) Diffusion and ecological problems: mathematical models. Springer-Verlag, New York

Olson DB (2001) Biophysical dynamics of western transition zones: a preliminary synthesis. Fish Oceanogr 10:133-150

Reynolds RW, Smith TM (1994) Improved global sea surface temperature analyses using optimum interpolation. J Clim 7:929-948

Royer F (2005) Observation et modélisation de la dynamique spatiale du thon rouge dans la région du Gulf Stream apports des analyses Mercator dans le suivi des marques archives. Mercator/Coriolis Group, Toulouse

Royer F, Fromentin JM, Gaspar P (2005) A state space model to derive bluefin tuna movement and habitat from archival tags. Oikos 109:473-484

Royer F, Wilson S, Lutcavage M (2006) Migratory and depth behaviour of bluefin tuna in the Gulf Stream area: how Mercator can help in revealing habitat use by pelagic species. Mercator Quart Newslett 20:7-11

Shaffer SA, Tremblay Y, Awkerman JA, Henry RW and others (2005) Comparison of light- and SST-based geolocation with satellite telemetry in free-ranging albatrosses. Mar Biol 147:833-843

Sibert JR, Fournier DA (2001) Possible models for combining tracking data with conventional tagging data. In: Sibert JR, Nielsen JL (eds) Electronic tagging and tracking in marine fisheries. Kluwer Academic Publishers, Dordrecht, p 443-456

Sibert J, Hampton J, Fournier D (1996) Skipjack movement and fisheries interaction in the western Pacific. In: Shomura RS, Majkowski J, Harman RF (eds) The 2nd FAO expert consultation on interactions of Pacific Ocean tuna fisheries, 23-31 January 1995, Shimizu, Japan. FAO, Rome, p 18

> Sibert JR, Hampton J, Fournier DA, Bills PJ (1999) An advection-diffusion-reaction model for the estimation of fish movement parameters from tagging data, with application to skipjack tuna (Katsuwonus pelamis). Can J Fish Aquat Sci 56:925-938

Sibert JR, Musyl MK, Brill RW (2003) Horizontal movements of bigeye tuna (Thunnus obesus) near Hawaii determined by Kalman filter analysis of archival tagging data. Fish Oceanogr 12:141-151

Sibert JR, Lutcavage ME, Nielsen A, Brill RW, Wilson SG (2006) Inter-annual variation in large-scale movement of Atlantic bluefin tuna (Thunnus thynnus) determined from pop-up satellite archival tags. Can J Fish Aquat Sci 63: 2154-2166 
Smith P, Goodman D (1986) Determining fish movements from an 'archival' tag: precision of geographical positions made from a time series of swimming temperature and depth. NOAA NMFS SWFC Tech Memo 60:1-13

Stone M (1974) Cross-validatory choice and assessment of statistical predictions. J R Stat Soc B 36:111-147

> Teo SLH, Boustany A, Blackwell S, Walli A, Weng KC, Block BA (2004) Validation of geolocation estimates based on light level and sea surface temperature from electronic

Editorial responsibility: Jon Hare,

Narragansett, Rhode Island, USA tags. Mar Ecol Prog Ser 283:81-98

The Ring Group (1981) Gulf Stream cold core rings: their physics, chemistry and biology. Science 212:1091-1100

> Wilson SG, Lutcavage ME, Brill RW, Genovese MP, Cooper AB, Everly AW (2005) Movements of bluefin tuna (Thunnus thynnus) in the northwestern Atlantic Ocean recorded by pop-up satellite archival tags. Mar Biol 146:409-423

Worton B (1987) A review of models of home range for animal movement. Ecol Model 38:277-298

Submitted: February 22, 2007; Accepted: March 27, 2008 Proofs received from author(s): July 10, 2008 